\title{
Phylogeography and evolutionary history of the Crocidura olivieri complex (Mammalia, Soricomorpha): from a forest origin to broad ecological expansion across Africa
}

François Jacquet ${ }^{1 *}$, Christiane Denys ${ }^{1}$, Erik Verheyen ${ }^{2,3}$, Josef Bryja ${ }^{4,5}$, Rainer Hutterer ${ }^{6}$, Julian C Kerbis Peterhans ${ }^{7,8}$, William T Stanley ${ }^{8}$, Steven M Goodman ${ }^{8,9}$, Arnaud Couloux ${ }^{10}$, Marc Colyn ${ }^{11}$ and Violaine Nicolas ${ }^{1}$

\begin{abstract}
Background: This study aims to reconstruct the evolutionary history of African shrews referred to the Crocidura olivieri complex. We tested the respective role of forest retraction/expansion during the Pleistocene, rivers (allopatric models), ecological gradients (parapatric model) and anthropogenic factors in explaining the distribution and diversification within this species complex. We sequenced three mitochondrial and four nuclear markers from 565 specimens encompassing the known distribution of the complex, i.e. from Morocco to Egypt and south to Mozambique. We used Bayesian phylogenetic inference, genetic structure analyses and divergence time estimates to assess the phylogenetic relationships and evolutionary history of these animals.

Results: The C. olivieri complex (currently composed of C. olivieri, C. fulvastra, C. viaria and C. goliath) can be segregated into eight principal geographical clades, most exhibiting parapatric distributions. A decrease in genetic diversity was observed between central and western African clades and a marked signal of population expansion was detected for a broadly distributed clade occurring across central and eastern Africa and portions of Egypt (clade IV). The main cladogenesis events occurred within the complex between 1.37 and $0.48 \mathrm{Ma}$. Crocidura olivieri sensu stricto appears polyphyletic and C. viaria and C. fulvastra were not found to be monophyletic.

Conclusions: Climatic oscillations over the Pleistocene probably played a major role in shaping the genetic diversity within this species complex. Different factors can explain their diversification, including Pleistocene forest refuges, riverine barriers and differentiation along environmental gradients. The earliest postulated members of the complex originated in central/eastern Africa and the first radiations took place in rain forests of the Congo Basin. A dramatic shift in the ecological requirements in early members of the complex, in association with changing environments, took place sometime after 1.13 Ma. Some lineages then colonized a substantial portion of the African continent, including a variety of savannah and forest habitats. The low genetic divergence of certain populations, some in isolated localities, can be explained by their synanthropic habits. This study underlines the need to revise the taxonomy of the C. olivieri complex.
\end{abstract}

Keywords: Crocidura olivieri, Diversification, Forest refuge, Molecular dating, Phylogeography, Pleistocene climate changes, Riverine barrier, Soricidae, Systematics

\footnotetext{
* Correspondence: fr.jacquet@gmail.com

${ }^{1}$ Institut de Systématique, Évolution, Biodiversité, ISYEB UMR 7205 - CNRS,

MNHN, UPMC, EPHE, Muséum National d'Histoire Naturelle, Sorbonne

Universités, 57 rue Cuvier, CP 51, 75005 Paris, France

Full list of author information is available at the end of the article
} 


\section{Background}

Climatic oscillations during the Pleistocene are known to have had a dramatic role in shaping the diversity and distribution of many African plant and animal species $[1,2]$. Several large-scale studies that tested this hypothesis have been carried out on large African mammals [3-5]. However, these animals are vagile and often broadly disperse or have large home ranges. Therefore, small mammals are excellent models for testing patterns of pan-African biogeography. There have been a few studies on sub-Saharan rodents [6-8], but shrews (Soricidae), a group known to have been used elsewhere to test Pleistocene climate oscillation models [9], have not been examined across broad ecological areas on the continent. These animals have short life spans, rapid reproduction cycles, low dispersal abilities and respond quickly to environmental changes [10], and are therefore a good model to investigate climate-driven models of diversification. All available genetic studies of African shrews focussed on taxa with relatively small geographical distributions (e.g. [9]). Members of the Crocidura olivieri (Lesson, 1827) complex [11], which have notably large body size for shrews and can weigh up to $65 \mathrm{~g}$ [12], are a rare example of a widespread Afrotropical soricid taxon. Members of the C. olivieri complex occur in a variety of habitats, including tropical rain forests, marshes, savannah and montane areas [12]. Therefore, this group is a potentially excellent model to test how climatic oscillations and associated changes in vegetation during the Pleistocene influenced their distribution and diversification.

Models employed to understand diversification events within vertebrates faunas are too numerous to review in detail here. By and large, hypotheses concerning factors that promote speciation in tropical faunas have been preoccupied with the geographical context of speciation and fall into two categories: allopatric and parapatric models. With allopatric models, extrinsic barriers to gene flow lead to the separation of sub-populations, which evolve differently associated with genetic drift and natural selection. For example, the "Pleistocene forest refuge" hypothesis, originally formulated for tropical South America and then applied to the Afrotropics, postulates that during the last $2.5 \mathrm{Myr}$, climatic oscillations caused phases of contraction and expansion of different vegetation types [1]. Severe and long-lasting dry and cold periods reduced forests to isolated remnants or 'refuges' allowing diversification and allopatric speciation [1]. The "riverine barrier" hypothesis argues that rivers acted as physical barriers associated with the distribution of certain taxa, promoting diversification [13]. Allopatric models have been invoked to explain the current distribution and diversity of African small mammal species [10,14-16]. The gradient model of diversification (parapatric or ecotonal model) has been proposed as an alternative to allopatric models [17]. It suggests that strong environmental gradients result in adaptive divergence and speciation for taxa tolerant of a broad range of habitats. A recent study has emphasized the role of habitat gradients in lineage diversification in the African rodent Cricetomys [7].

The taxonomy of the C. olivieri complex has been discussed for almost a century but uncertainties remain. Species currently considered valid within the C. olivieri complex are distributed across different habitats: C. goliath Thomas, 1906 is endemic to rain forests of the Congo Basin, C. viaria (I. Geoffroy, 1834) and C. fulvastra (Sundevall, 1843) are encountered in the Sudanian savannah from Morocco to Kenya and from Mali to Ethiopia, respectively, and C. olivieri is widespread across portions of the African continent [12].

The specific aims of this study are: 1) to provide a greater understanding of the systematics of African giant shrews of the C. olivieri complex, specifically specimens identified based on morphology as C. olivieri, C. viaria, C. fulvastra or C. goliath; 2) to test for the respective roles of forest retraction/expansion, rivers (allopatric models), ecological gradients (parapatric model) and anthropogenic factors in explaining the diversification and current distribution of the different lineages. In order to infer biogeographical scenarios at the scale of the African continent and to answer questions concerning possible factors promoting diversification within the complex, we used data from three mitochondrial and four nuclear markers and conducted phylogenetic and population genetics analyses on animals originating from most of its geographical range (Figure 1).

\section{Results}

\section{Phylogenetic relationships}

Based on Bayesian Inference of combined data from the seven markers (Figure 2 and Additional file 1) the C. olivieri complex (specimens morphologically identified as $C$. olivieri, C. viaria, C. fulvastra C. goliath or C. somalica) forms a highly supported monophyletic group ( $\mathrm{pp}=$ posterior probability $>0.95$ ). This complex is the sister clade to a clade composed of $C$. flavescens and C. hirta. The clade composed of these seven species is reciprocally monophyletic with respect to $C$. lamottei. Within the C. olivieri complex, eight main clades can be identified. Clades I, II, IV, VI and VIII are composed of specimens assigned to C. olivieri based on morphology. Specimens assigned to $C$. viaria and C. fulvastra are gathered in clade III but do not form two monophyletic groups. Phylogenetic relationships are poorly resolved within this clade. Clade V comprises all specimens originally identified as C. goliath and clade VII the two specimens morphologically identified as $C$. somalica. Clades I + II, I-to-III, I-to-IV, VI + VII and I-to-VII are strongly monophyletic. Clade I-to-V is not supported ( $\mathrm{pp}=0.84)$. 
a)

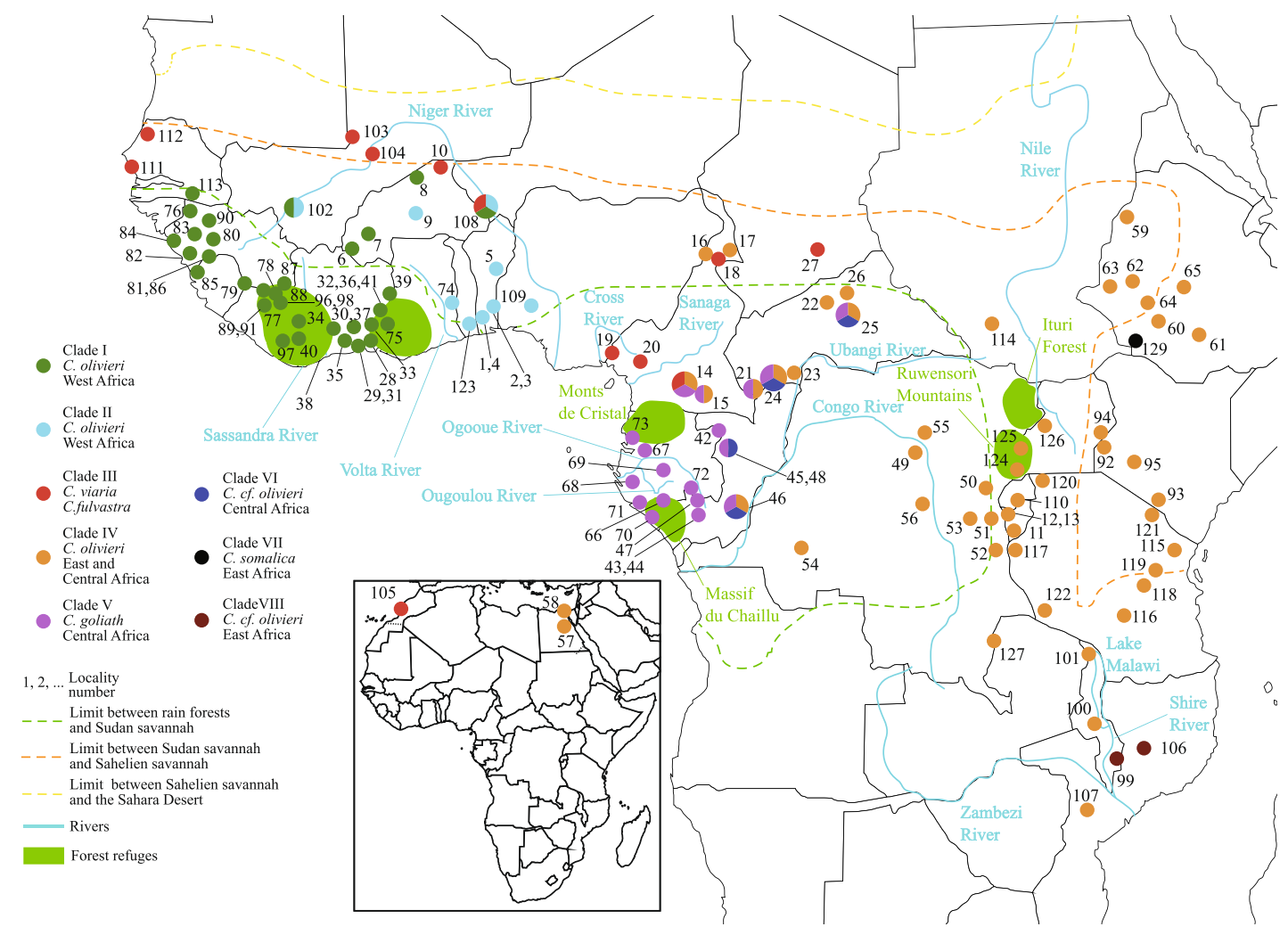

b)

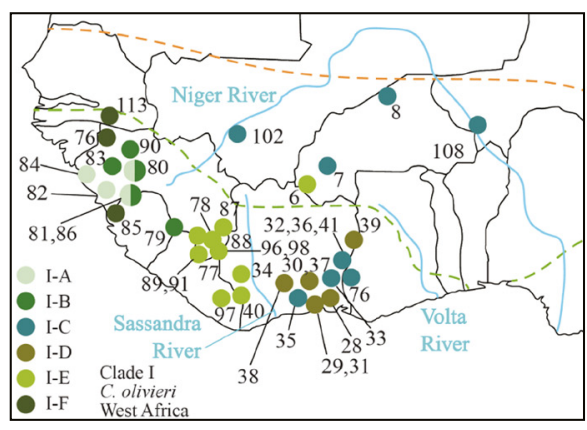

d)

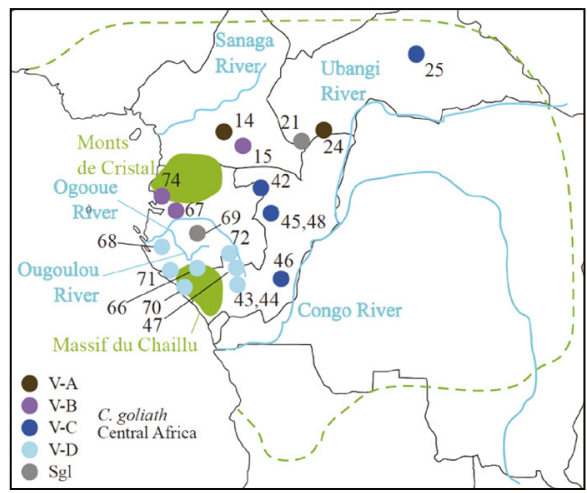

c)

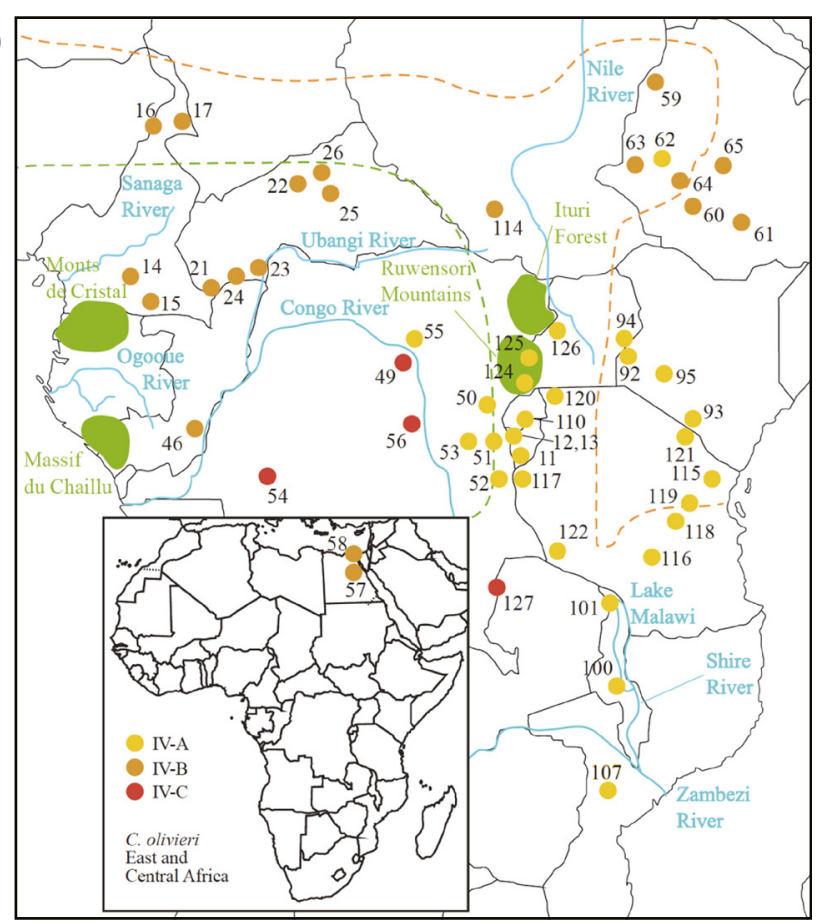

Figure 1 (See legend on next page.) 
(See figure on previous page.)

Figure 1 Sampling points and clade distributions. Map of sampling points showing the distribution of the phylogenetic clades identified in the Bayesian phylogenetic analyses: 8 main clades of the clade VII: C. somalica and clade VIII: C. hera complex (a), subclades within clade I (1b), subclades within clade IV (c) and subclades within clade V (d). Ecological divisions based on White's (1981) vegetation map. See Additional file 6 for localities names and GPS coordinates.

The topology obtained through analysis of mtDNA data (Additional files 2 and 3 ) is very similar to the former, some nodes not recovered (monophyly of clade I-to-VII) or only poorly supported (clades VI + VII and I-to-III). Based on nuclear data (Additional files 4 and 5), the specimens referred to C. olivieri, C. viaria, C. fulvastra, C. goliath, C. somalica, $C$. flavescens and $C$. hirta form a monophyletic group. In the $C$. olivieri complex, only clades VI $(\mathrm{pp}=0.90)$ and VIII $(\mathrm{pp}=0.99)$ can be retrieved (specimens of clade VII could not be included because the nuclear markers did not be amplify). The other clades (I to V) were not recovered, presumably because of low variability in the nuclear data. Crocidura hirta forms a highly supported clade that is reciprocally monophyletic with $C$. flavescens.

No mtDNA haplotype was shared between clades I to VIII. Several main clades shared between them a single nuclear haplotype: clades I, II and III for BRCA1; clades I and III for RIOK3; clades I and II, clades IV and V, clades IV and VIII and clades I, II and IV for HDAC2; and clades I, II, III, IV and V, clades IV and VI and clades IV and V for STAT5A.

\section{Phylogeography of the C. olivieri complex}

Individual specimens from the eight main clades in the C. olivieri complex can occur in sympatry, especially in central Africa (Figure 1). Six subclades can be identified within clade I, but phylogenetic relationships are not resolved. Clade I is composed of specimens obtained at forest or mixed forest-savannah sites (except subclade I-C also found in savannah) of western Africa (Senegal, Guinea, Liberia, Côte d'Ivoire, western Ghana, southern Niger, Burkina Faso and southwestern Mali), including individuals trapped in houses. Individuals placed in subclades I-C and I-D ( $\mathrm{pp}=0.97)$ occur on the left bank (following the watercourse from upstream to downstream) of the Sassandra River in western Côte d'Ivoire and specimens of subclade I-E (pp = 0.94) on the right bank (except one specimen captured further north). Clades I-D and I-E are sister clades with a low node support value ( $\mathrm{pp}=0.83$ ).

Clade II includes specimens, which were trapped in the Sudanian savannah zone, north of the Guinean forest block and in the Dahomey Gap in Ghana, Benin, Togo, Nigeria, southern Niger, Burkina Faso and southwestern Mali. Clade III encompasses all sequenced individuals identified as C. viaria (Morocco, Senegal, southwestern Niger, northern Burkina Faso and southern Cameroon) and C. fulvastra (Chad and northern Cameroon); these specimens were collected on the northern fringe of the Sudanian and Sahelian savannah zones, except for animals from southern Cameroon obtained in forests, croplands and oil palm plantations.

Clade IV is composed of specimens obtained in a broad range of habitats (forest, cropland, garden and savannah). The geographic range of this species group extends through- out central and eastern Africa with isolated localities in Egypt (the type locality of $C$. olivieri). The subclade IV-A ( $\mathrm{pp}=0.92)$ is composed of specimens from the east and southeast of the continent, all of them from the right bank of the Congo River (Figure 1). The northern subclade IV-B $(\mathrm{pp}=0.99)$ is encountered in Cameroon, CAR, eastern Congo, Egypt, Ethiopia and southern Sudan, on the right bank of the Congo and Ubangi Rivers. The subclade IV-C (pp = 0.97) is found in DRC and northeastern Zambia, on the left bank of the Congo River, except for specimens from the Ntumbachushi Falls (loc. 128). Clades IV-A and IV-B appear as sister clades but this relationship is not supported ( $\mathrm{pp}=0.50$ ).

Specimens of clade $\mathrm{V}$ originate from the central African rain forests on the right bank of the Ubangi-Congo River. Subclades V-B (southern Cameroon and northern Gabon; $\mathrm{pp}=0.62$ ) and V-D (southern Gabon and southwestern Congo; pp $=0,99)+$ specimen R16063 (Makande, Gabon) exhibit an allopatric distribution on each side of the Ogooué River: subclade V-B occurs on the left bank and subclade V-D and the isolated specimen on the right bank. Makande is situated between the Ogooué River and one of its tributaries, the Ougoulou River. The individuals representing clade VI originate from Congo and CAR rain forest. Several subclades are observed within this clade but specimens do not cluster by their geographical positions. They are largely sympatric with $C$. goliath (clade V).

Specimens of clade VII originate from mesic places in the Mago National Park in southwestern Ethiopia, where they were trapped in plain savannah with dense shrubs. Clade VIII is composed of specimens from northern Mozambique and southern Malawi that were obtained in montane forest 'islands' including gallery forests. This clade is bounded by the Shire River to the west, the Zambezi River to the south, open savannah woodland to the east and Lake Malawi to the north.

\section{Genetic distances}

The mean percentage of cytb sequence K2P divergence between various clades of the complex ranges from $1.34 \%$ (between clades I and II) to $4.90 \%$ (between clades V and VII). Within clades, the mean percent divergence ranges from $0.32 \%$ (clade VII) to $1.78 \%$ (clade IV) (Table 1a). 


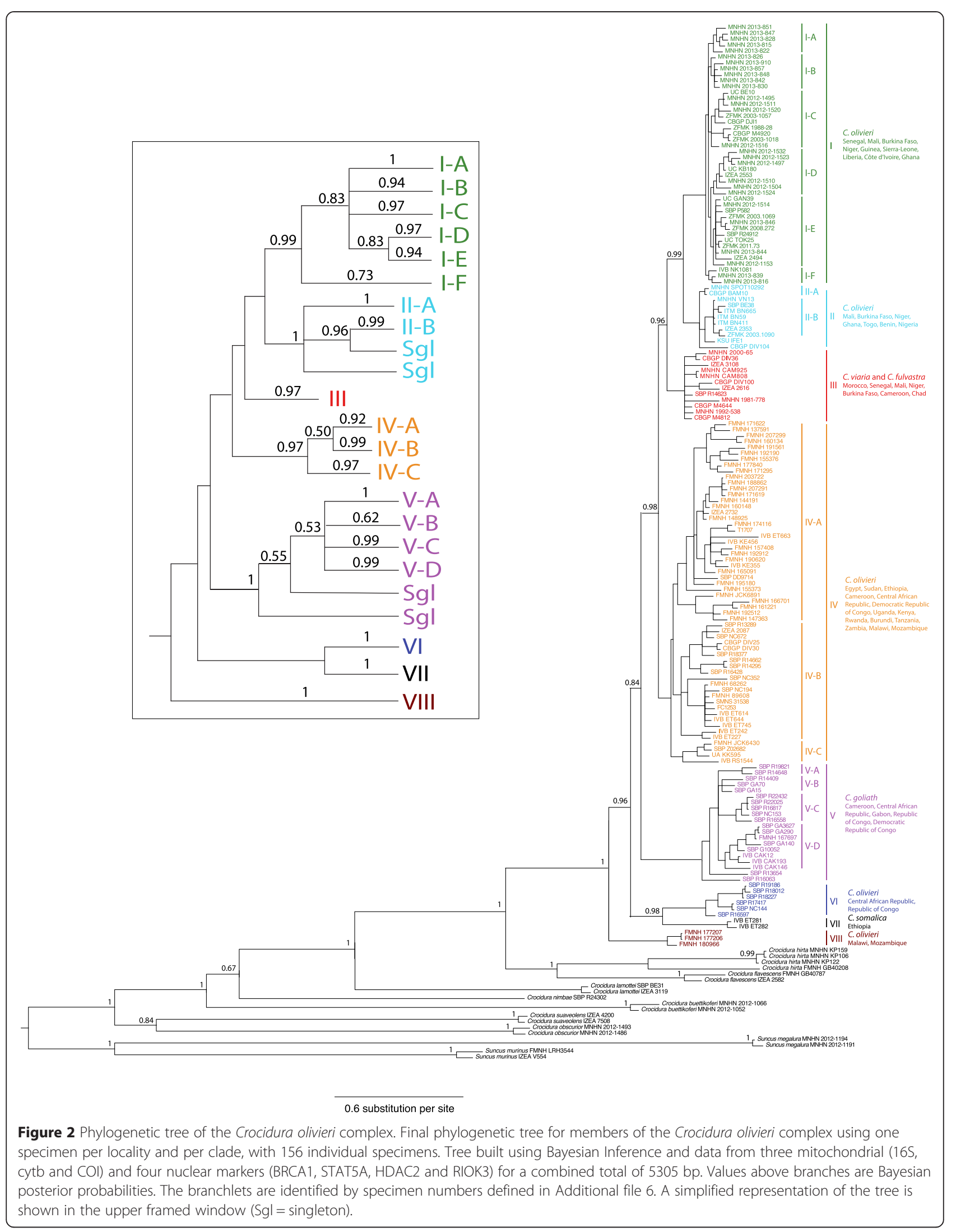


Table 1 Genetic distances within the Crocidura olivieri complex

\begin{tabular}{|c|c|c|c|c|c|c|c|c|}
\hline & 1 & II & III & IV & v & VI & VII & VIII \\
\hline \multicolumn{9}{|l|}{ a) } \\
\hline \multirow[t]{2}{*}{ । } & $0.45[0-1.0]$ & 1.34 & 1.50 & 2.26 & 4.13 & 3.98 & 4.43 & 3.51 \\
\hline & $0.54[0-1.6]$ & {$[0.6-2.1]$} & {$[0.9-3.0]$} & {$[1.2-3.4]$} & {$[2.9-5.2]$} & {$[3.2-4.7]$} & {$[3.5-5.6]$} & [3.0-4.2] \\
\hline \multirow[t]{2}{*}{$\|$} & 1.61 & $\mathbf{0 . 5 1}[0-1.4]$ & 2.01 & 2.70 & 4.48 & 4.26 & 4.78 & 3.99 \\
\hline & {$[1.0-2.7]$} & $0.56[0-1.7]$ & [1.1-3.0] & {$[1.5-3.5]$} & [2.8-5.8] & [3.0-5.2] & {$[4.1-5.5]$} & {$[3.0-4.7]$} \\
\hline \multirow[t]{2}{*}{ III } & 1.91 & 2.35 & $1.12[0-1.9]$ & 2.43 & 4.36 & 4.35 & 4.82 & 3.79 \\
\hline & {$[1.0-3.6]$} & {$[1.5-4.2]$} & $1.40[0-2.9]$ & {$[1.6-3.4]$} & [3.1-5.2] & {$[3.5-5.3]$} & [3.6-6.8] & [3.1-4.6] \\
\hline \multirow[t]{2}{*}{ IV } & 2.62 & 2.92 & 2.82 & $1.78[0-2.7]$ & 4.65 & 4.58 & 4.78 & 3.98 \\
\hline & {$[1.5-4.2]$} & [2.1-4.3] & {$[1.6-4.2]$} & $1.95[0-4.0]$ & [3.3-5.4] & {$[3.5-5.4]$} & [4.1-5.6] & [3.2-4.5] \\
\hline \multirow[t]{2}{*}{ V } & 4.52 & 4.69 & 4.75 & 4.67 & $\mathbf{1 . 2 6}[0.1-2.3]$ & 4.78 & 4.90 & 4.79 \\
\hline & {$[3.5-5.7]$} & [3.9-6.6] & {$[3.5-6.0]$} & {$[3.5-6.0]$} & $1.12[0-2.4]$ & {$[4.1-5.8]$} & {$[4.2-5.6]$} & {$[4.1-5.6]$} \\
\hline \multirow[t]{2}{*}{$\mathrm{Vl}$} & 4.54 & 4.66 & 4.91 & 4.83 & 4.92 & $\mathbf{0 . 6 5}[0.5-0.8]$ & 3.89 & 4.09 \\
\hline & [3.5-5.6] & {$[4.0-5.7]$} & {$[4.0-6.4]$} & {$[3.9-6.6]$} & {$[4.0-6.2]$} & $\mathbf{0 . 6 3}[0-1.5]$ & [3.6-4.4] & [3.9-4.3] \\
\hline \multirow[t]{2}{*}{ VII } & 4.22 & 4.57 & 4.60 & 4.57 & 4.68 & 3.75 & 0.32 & 3.58 \\
\hline & {$[3.4-5.2]$} & {$[4.0-5.2]$} & {$[3.4-6.4]$} & [3.9-5.3] & {$[4.0-5.2]$} & [3.4-4.1] & 0.30 & [3.4-3.9] \\
\hline \multirow[t]{2}{*}{ VIII } & 3.92 & 4.19 & 4.20 & 4.08 & 4.69 & 4.14 & 3.45 & 0.47 \\
\hline & [2.3-5.1] & [3.8-5.0] & [3.3-5.9] & [3.3-5.3] & [3.9-5.4] & [3.8-5.1] & [3.2-3.8] & 0.47 \\
\hline \multicolumn{9}{|l|}{ b) } \\
\hline \multirow[t]{2}{*}{ I } & $0.75[0-1.4]$ & 2.59 & 2.80 & 3.28 & 3.93 & 5.23 & 5.09 & 4.82 \\
\hline & $\mathbf{0 . 7 5}[0-1.4]$ & [1.4-3.4] & {$[0.5-3.7]$} & [1.6-4.6] & [1.6-6] & [3.8-5.7] & [3.3-5.8] & [3.8-5.3] \\
\hline \multirow[t]{2}{*}{$\|$} & 2.54 & $\mathbf{0 . 6 5}[0-1.6]$ & 2.15 & 2.80 & 4.62 & 4.48 & 4.30 & 4.65 \\
\hline & [1.4-3.3] & $\mathbf{0 . 6 3}[0-1.5]$ & {$[1.2-3.0]$} & [1.6-4.1] & {$[3.5-5.2]$} & {$[4.0-4.8]$} & [3.6-4.8] & [4.0-5.2] \\
\hline \multirow[t]{2}{*}{ III } & 2.79 & 2.10 & $0.49[0-1.0]$ & 2.37 & 4.24 & 3.71 & 3.66 & 4.02 \\
\hline & [1.4-3.6] & [1.2-2.9] & $\mathbf{0 . 4 9}[0-1.0]$ & [1.6-3.8] & [3.5-4.9] & [3.5-4.0] & [3.1-4.3] & [3.8-4.5] \\
\hline \multirow[t]{2}{*}{ IV } & 3.23 & 2.77 & 2.37 & $1.39[0-3.0]$ & 4.59 & 4.06 & 3.78 & 4.47 \\
\hline & {$[1.5-5.8]$} & [1.5-4.9] & [1.7-4.9] & $1.31[0-2.8]$ & {$[3.0-6.0]$} & {$[3.5-5.0]$} & [3.0-4.8] & [3.3-5.5] \\
\hline \multirow[t]{2}{*}{ V } & 4.91 & 4.46 & 4.08 & 4.44 & $1.20[0-2.2]$ & 4.55 & 4.45 & 4.43 \\
\hline & [3.5-5.7] & [3.4-4.9] & [3.4-4.7] & [3.1-5.7] & $1.15[0-1.7]$ & [4.0-5.1] & [3.8-5.0] & [3.7-5.1] \\
\hline \multirow[t]{2}{*}{$\mathrm{Vl}$} & 4.92 & 4.28 & 3.74 & 4.06 & 4.38 & $\mathbf{0 . 2 1}[0-0.3]$ & 2.16 & 4.10 \\
\hline & {$[3.5-5.6]$} & [3.4-4.9] & {$[3.4-4.6]$} & {$[2.9-5.4]$} & [3.8-4.8] & $\mathbf{0 . 3 4}[0-1.1]$ & {$[2.0-2.2]$} & {$[4.1-4.1]$} \\
\hline \multirow[t]{2}{*}{ VII } & 4.88 & 4.14 & 3.54 & 3.68 & 4.30 & 2.84 & 0.30 & 3.60 \\
\hline & [3.2-5.5] & [3.5-4.6] & [3.0-4.1] & [2.9-4.6] & [3.8-4.8] & [2.0-4.6] & 0.30 & \\
\hline \multirow[t]{2}{*}{ VIII } & 4.61 & 4.42 & 3.86 & 4.31 & 4.27 & 4.04 & 3.50 & 0.20 \\
\hline & {$[3.7-5.1]$} & [3.8-4.9] & [3.7-4.3] & [3.2-5.2] & {$[3.5-4.9]$} & [3.8-4.4] & & 0.20 \\
\hline
\end{tabular}

Genetic distances (K2P above and uncorrected p-distances below diagonal) between and within clades of the $\mathrm{C}$. olivieri complex for cytb (1a) and COI markers (1b) with mean and range within brackets.

For COI, mean percentages between clades ranges from $2.15 \%$ (between clades II and III) to 5.23\% (between clades I and VI). Within clades, the mean percent divergence ranges from $0.20 \%$ (clade VIII) to $1.39 \%$ (clade IV) (Table 1b).

\section{Divergence time estimates}

Phylogenetic relationships between clades I to VIII inferred from divergence time estimates analysis using
BEAST were the same as those obtained with Bayesian analysis based on concatenated data from the seven markers. The time to the most recent common ancestor of the C. olivieri complex is estimated after $1.37 \mathrm{Ma}$ (highest posterior density (HPD) interval containing 95\% of the sampled values: 1.00-1.75, Figure 3). This corresponds to the split leading to the separation of clade VIII. The bifurcation between clades I-to-V and VI + VII is dated after $1.25 \mathrm{Ma}(0.94-1.58)$ and that between clade 


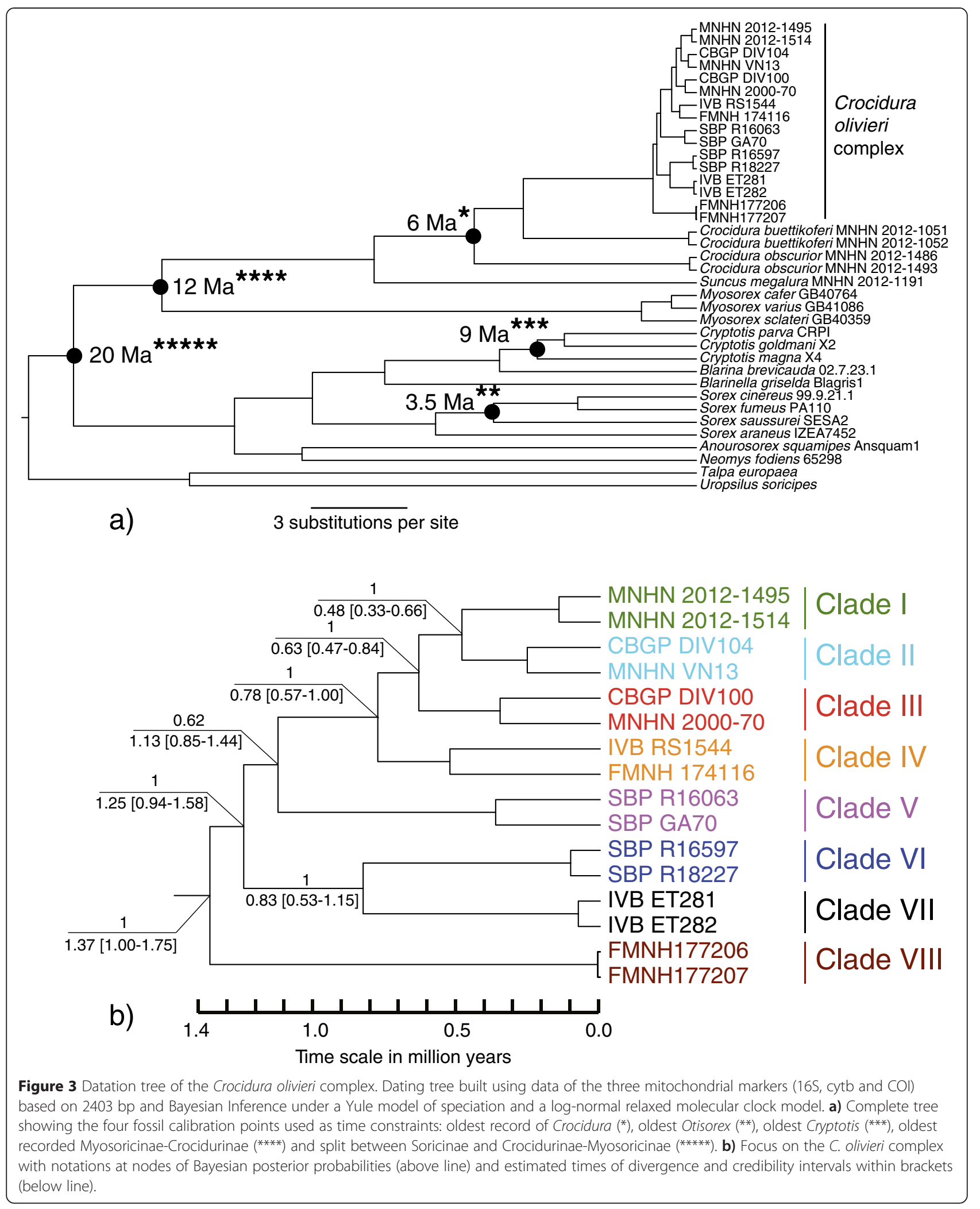

$\mathrm{V}$ and I-to-IV after $1.13 \mathrm{Ma}(0.85-1.44)$. The most recent divergence event corresponds to the split between clades I and II and is dated after $0.48 \mathrm{Ma}(0.33-0.66)$.
Divergence time estimates inferred using a standard mammalian mutation rate of $2.2 \%$ per Myr [18] are between 16.7 and $31.7 \%$ lower than those obtained with 
fossil calibration points. The time to the most recent common ancestor of the complex is estimated after $1.09 \mathrm{Ma}$ (0.90-1.29). The bifurcation between clades Ito-V and VI + VII is dated after $1.01 \mathrm{Ma}(0.85-1.19)$ and that between clade $\mathrm{V}$ and I-to-IV after $0.92 \mathrm{Ma}(0.75-$ 1.08). The most recent divergence event corresponds to the split between clades I and II and is dated after $0.40 \mathrm{Ma}(0.30-0.51)$. All these estimates fall within 95\% intervals inferred from the analysis using calibration points. We therefore chose to base our biogeographic scenario hypotheses on fossil calibrations.

\section{Historical demography}

Based on mitochondrial data (16S, cytb and COI), the nucleotide diversity $(\times 100)$ ranges from 0.296 (clade VI) to 1.584 (clade IV) with a decrease from clade IV to clade I. Haplotype diversity ranges from 0.673 (clade VI) to 0.993 (clade V) with a decrease from clade $\mathrm{V}$ to clade II (Table 2). Based on mismatch distributions, a signal of demographic expansion was detected for all clades except for clade VI. The mode of the curve (tau) showed the highest value for clade IV, followed by clade $\mathrm{V}$ and the lowest value for clade I. A signal of spatial expansion was detected for all clades. The Fu's Fs neutrality tests indicated significant population growth for clades I, IV and V. A spatial expansion was detected for clades IV (significant $F$ s, whereas $F^{*}$ and $D^{*}$ were not significant). Extended skyline plot analyses revealed demographic growth for clades I, III and IV based on numbers of population changes ( 1 and 2 for clade I, 1 for clade III and 1, 2 and 3 for clade IV) [19].

\section{Discussion}

Alternative models to explain speciation and diversification events within the Crocidura olivieri complex

\section{Forest refuge theory}

All divergence events within the C. olivieri complex occurred after 1.37 (1.00-1.75) Ma, i.e. when the periodicity of glacial cycles switched from 41,000 to 100,000 years and induced prolonged periods of aridity on Africa [2]. Divergence between clades I-to-V, VI, VII and VIII occurred around 0.83-1.37 (0.54-1.75) Ma. These dates should be interpreted with caution given the wide divergence time intervals. On the African continent, the period around $1 \mathrm{Ma}$ was characterized by notable aridity coinciding with a reduction of lowland forests and an expansion of savannah biomes [20]. This period coincides with divergence events for other African forest mammals $[9,15,21]$. Given that clades V, VI and VIII include forest-dwelling animals (lowland forests for clades $\mathrm{V}$ and VI and montane forests for clade VIII) and that these clades have allopatric or parapatric distributions, most of the early divergence events within the complex are congruent with the "Pleistocene forest refuge" hypothesis [1]: several populations of the complex may have been isolated for long periods in distinct forest refuges, favouring allopatric diversification.

Table 2 Genetic structure indices within the Crocidura olivieri complex

\begin{tabular}{|c|c|c|c|c|c|c|c|c|c|c|c|c|c|}
\hline \multirow[t]{2}{*}{ Clade } & \multirow[t]{2}{*}{$N$} & \multirow[t]{2}{*}{$\mathrm{Np}$} & \multirow[t]{2}{*}{$\mathrm{Nh}$} & \multirow[t]{2}{*}{$\mathrm{Hd}$} & \multirow[t]{2}{*}{$\mathrm{Pi}$} & \multirow[t]{2}{*}{$k$} & \multicolumn{3}{|c|}{$\begin{array}{l}\text { Mismatch distribution } \\
\text { goodness-of-fit test }(\mathrm{P})\end{array}$} & \multirow[t]{2}{*}{$\begin{array}{l}\text { Fu and Li's D } \\
\text { test }\end{array}$} & \multirow[t]{2}{*}{$\begin{array}{l}\text { Fu and Li's F } \\
\text { test }\end{array}$} & \multirow[t]{2}{*}{$\begin{array}{l}\text { Fu's Fs } \\
\text { test }\end{array}$} & \multirow[t]{2}{*}{$\begin{array}{l}\text { Tajima's D } \\
\text { test }\end{array}$} \\
\hline & & & & & & & Dem exp & Tau & $\overline{\text { Spatial exp }}$ & & & & \\
\hline \multirow[t]{2}{*}{ I } & 90 & 115 & 59 & 0.969 & 0.447 & 9.426 & 0.25 & 10.4 & 0.41 & -2.08 & -2.45 & -24.57 & -1.95 \\
\hline & & & & & & & & & & $P>0.05$ & $P<0.05$ & SS $=1.00$ & $P<0.05$ \\
\hline \multirow[t]{2}{*}{$\|$} & 17 & 37 & 11 & 0.882 & 0.473 & 9.868 & 0.41 & 23.6 & 0.65 & 0.37 & 0.17 & 0.62 & -0.40 \\
\hline & & & & & & & & & & $P>0.1$ & $P>0.1$ & $\mathrm{sS}=0.06$ & $P>0.1$ \\
\hline \multirow[t]{2}{*}{ |II } & 17 & 56 & 14 & 0.978 & 0.783 & 16.63 & 0.35 & 20.2 & 0.75 & 0.15 & 0.13 & -1.41 & 0.017 \\
\hline & & & & & & & & & & $P>0.1$ & $P>0.1$ & SS $=0.93$ & $P>0.1$ \\
\hline \multirow[t]{2}{*}{ IV } & 95 & 276 & 72 & 0.991 & 1.584 & 33.87 & 0.85 & 41.6 & 0.99 & -1.06 & -1.42 & -14.43 & -1.25 \\
\hline & & & & & & & & & & $P>0.1$ & $P>0.1$ & Ss $=1.00$ & $P>0.1$ \\
\hline \multirow[t]{2}{*}{ V } & 37 & 158 & 33 & 0.993 & 0.911 & 19.72 & 0.23 & 24.4 & 0.48 & -2.98 & -3.06 & -8.21 & -1.79 \\
\hline & & & & & & & & & & $P<0.05$ & $P<0.05$ & SS $=1.00$ & $P<0.05$ \\
\hline \multirow[t]{2}{*}{ Vl } & 11 & 19 & 4 & 0.673 & 0.296 & 6.582 & 0.009 & - & 0.44 & -0.40 & -0.32 & 4.35 & 0.07 \\
\hline & & & & & & & & & & $P>0.1$ & $P>0.1$ & $s s=0.06$ & $P>0.1$ \\
\hline
\end{tabular}

Genetic diversity, mismatch distributions and neutrality estimates for the main clades of members of the $C$. olivieri complex identified in the phylogenetic analyses based on three combined mitochondrial markers (16S, cytb and $\mathrm{COI}$ ). Data include number of specimens (N), number of polymorphic sites (Np), number of distinct haplotypes (Nh), haplotype diversity (Hd), nucleotide diversity (Pi, expressed as percentages, i.e. $0.001=0.1 \%$ ) and average number of pairwise nucleotide differences (k). Values indicating a signal of demographic or range expansion are in bold ( $P$-value $=P<0.05$; ss $=$ Strobeck's statistic $>0.95$ for Fu's Fs test). Tau is the mode of the curve of the mismatch distribution when a signal of demographic expansion is detected. It is proportional to the time since expansion. Clades VII and VIII are not included owing to a low number of specimens ( $\mathrm{n}=2$ and $n=3$, respectively). 
Several central Africa refuges have been identified and provide insight into the current distribution of clades $\mathrm{V}$, VI and VIII. Two refuges were described in the western part of the Congo Basin, the first near the Massif du Chaillu in southern Gabon and southern Congo and the second near Monts de Cristal in northern Gabon, Equatorial Guinea and southern Cameroon [20,22]. Within C. goliath, the distributions of clades V-B (not supported) and V-D are coincident with the Monts de Cristal and Massif du Chaillu refuges, respectively. Clade VIII is composed of members from two montane inselbergs, one in southern Malawi (Mt Mulanje) and the second in northern Mozambique (Mt Namuli), in the Malawi Rift. This rift forms a southern extension of the Albertine Rift. Their ancient age of divergence is consistent with this section of the Rift Valley being an early isolate from the main section of the Albertine Rift Valley to the north (and west). Two refuges occur on the Albertine Rift near the border of DRC and Uganda: the Ruwenzori Mountains and Ituri Forest [20,22].

Clade I is essentially encountered in Guinean forests. The phylogenetic relationships remain unresolved for the six clades I-A to I-F, which exhibit largely disjunct, but in some cases overlapping geographical ranges. This pattern is congruent with an ancestral population having experienced rapid habitat fragmentation, such as forest retraction during arid climatic phases, resulting in lineage sorting and then divergence between allopatric populations [15]. The genetic structure and distribution of clade I show similar patterns to that of the rodent Praomys rostratus [15], in which the observed distribution of two sister clades I-D and I-E fits the hypothesized areas of two Pleistocene forest refuges, one in southwestern Ghana and the other in Côte d'Ivoire, Liberia and southeastern Guinea [9,20,22]. However, this hypothesis has to be considered with caution owing to the weak support of the monophyly of clade I-D + I-E.

\section{Gradient model of diversification}

The split between clade $\mathrm{V}$ and clades I-to-IV is dated after $1.13 \mathrm{Ma}$ (0.85-1.44), which corresponds to a new geological period of aridity and forest retraction [2]. Diminishing forested habitats and the progression of savannah might have facilitated a niche displacement at the forest-savannah ecotone. As populations belonging to clade $\mathrm{V}$ are typically forest-dwelling, whereas those of clades I-to-IV are frequently trapped in savannah and secondarily in forests, an ecological gradient model of diversification [17] may be invoked to understand these divergence events. As the ancestral population of clades I to $\mathrm{V}$ probably inhabited central African forests (according to the topology of the different phylogenetic trees), dispersal is postulated to have occurred from forest habitat to a mosaic of habitats composed of forest-savannah, and then to savannah. This resulted in parapatric differentiation along an ecological gradient via natural selection.

The most recent successive splits of clades IV, III, II and I complex occurred after 0.78 (0.57-1.00), 0.63 (0.47-0.84) and 0.48 Ma (0.33-0.66). Each of these diversification events includes taxa currently showing parapatric distributions, with cases of syntopy at some localities. The distributions of these clades can be superimposed on the major African floristic zones (Figure 1) [23]: clade IV is recorded mainly from central African forests and croplands surrounded by a mosaic of forest and Sudanian savannah and woodlands of eastern Africa; clade III from drier Sudanian and Sahelian savannah; clade II from western African Sudanian savannah; and clade I mainly from Guinean forests. These geographical distributions occur along a geographical and ecological gradient and sister clades occupy adjacent and distinct habitats with some overlap; patterns typical of predictions from the gradient model of diversification [17]. It is hypothesized that the associated cladogenesis events occurred close to the current contact zones between these clades. These events may be related to the southward progression of the Sahara and Sahelian savannah during glacial cycles, as shown for Taterillus gerbils over the past $1 \mathrm{Myr}$ [24]. Although estimates of divergence times need to be interpreted with caution, we can assume that climatic oscillations during the Pleistocene probably played an important role in the diversification of the C. olivieri complex, as already proposed for several African rodents [15,24].

\section{Riverine barriers}

Rivers can promote allopatric diversification by separating a population into two vicariant subpopulations that form sister clades [13]. Such patterns can be observed within the C. olivieri complex and have been described in other African mammals: clades I and II and the genus Praomys along the Volta River [16]; clades IV-A + IV-B vs IV-C and other mammal taxa along the Congo-Ubangi River $[7,14]$. This hypothesis should be considered with caution owing to the weak support of the monophyly of clade IV-A + IV-B.

Rivers can also restrict gene flow between populations that have diverged through other means. When rivers are the proximal, but not the causal mechanism of diversification, distinct genetic clades can be observed on opposite banks but are not necessarily sister clades. In agreement with the river barrier hypothesis, we found clades V and VI to be geographically restricted to the right bank of the Congo-Ubangi River and clade IV-C restricted to the left bank. The specimen from Makandé forms a singleton group and its distribution appears 
restricted to the area between the Ogooue and Ougoulou Rivers. The Ogooué River is known to constrain the distribution of the primate Mandrillus sphinx [21]. Clade V is only found south of the Sanaga River, which is the distribution limit for numerous mammal species [5,21]. Within clade I, the Sassandra River seems to limit gene flow between clades situated on each side (clades I-C and I-D on the left side and clade I-E on the right side), as already observed in other small mammal $[9,15]$. It seems likely that large modern watercourses have remained stable over the past $1 \mathrm{Ma}$ with regards to their trajectory, but with variable water levels. Only few data are available concerning rivers' histories, which are often traced using phylogeographical patterns [25].

\section{From a forest origin to a wide ecological success throughout Africa}

\section{Origin of the C. olivieri complex in central/eastern Africa} and first radiation in the Congo Basin

Animals occurring within clades V to VIII, the most basal, are endemic either to eastern or central Africa, but the topology of the phylogenetic tree does not provide a precise signal as to the origin of the C. olivieri complex. Individuals associated with clades V and VI were captured in lowland rain forests of the Congo Basin, so the most likely scenario is that early members of the complex colonized this watershed. A radiation then occurred within forest ecosystems, probably correlated with increase in body size.

Only a few specimens of clades VI $(\mathrm{n}=15)$, VII $(\mathrm{n}=2)$ and VIII $(\mathrm{n}=3)$ were available and a possible explanation of their rarity could be competition. Indeed, distribution of clade VI seems to be limited to the easternmost fringe of the distribution of clade $\mathrm{V}$, i.e. $C$. goliath. No other basal lineage than clade VIII was found in the Albertine Rift and it can be speculated that they were replaced on most of Albertine and southern Rift mountains during Pleistocene by individuals of clade IVA, which represent the expanding population of animals with larger body size. Clade VIII thus represents a relict population. Another explanation to the low effectives of clades VI to VIII could be some form of habitat segregation due to strict ecological requirements. Indeed, specimens of clade VII were trapped only in mesic places in shrubby savannah and specimens of clade VIII only along streams in dense montane forest.

\section{Exit from forests approximately $1.13 \mathrm{Ma}$ and colonization of other habitats}

Specimens of clade I-to-IV are encountered in many habitats (forest, savannah, field, gardens and houses) of the African continent and from Senegal to Ethiopia and from Chad to South Africa, whereas clades V, VI and VIII would be restricted to Congolese or montane forests. These patterns support an important relaxing of habitat requirements after $1.13(0.85-1.44) \mathrm{Ma}$ and more precisely, a partial exit out of forest, congruent with the gradient model of diversification. This event may have dramatically expanded the dispersal abilities within the complex and could explain its subsequent ecological success across much of the African continent. A marked signal of recent population and range expansion was detected for clade IV. Crocidura olivieri (sensu stricto) is one of the most abundant shrew species in different small mammal communities [26,27].

\section{Colonization of northern and western Africa and secondary return to a forest habitat}

A pattern of colonization from the Congo Basin toward northern Africa and then western Africa is consistent with the asymmetric topology of the mitochondrial and concatenated trees (paraphyletic position of eastern and central African lineages that exhibit relatively longer branch lengths; [28]) and estimates of genetic diversity. A progressive decline in population nucleotide and haplotype diversity from central (clades IV and V) to western Africa (clades I and II) can be observed. Population expansion occurred earlier in central Africa (clade IV) than in western Africa (clades I to III). The colonization of western Africa is postulated to have started after $0.78 \mathrm{Ma}(0.57-1.00)$ (split between clades IV and I-to-III) and the ancestral population of clade I-toIII may have then expanded westward along the Sahelian savannah corridor (Figure 1). Interestingly, the recently diverged clade I is essentially encountered in Guinean forests, while its sister clade (clade II) is restricted to the surrounding Sudanian savannah, which we interpret as a return to the original forest habitat.

\section{The role of human movements in the dispersion of the $\mathrm{C}$. olivieri complex}

Specimens of clade I-to-IV were trapped in towns and villages and in some cases in houses (clades I and II). Owing to this previously reported synanthropic behaviour for members of the complex [29,30], human activities may have played a role in the dispersal of these animals. Specimens were captured in three isolated localities (Massa in Morocco, Kom Oshim and Abu Rawash in Egypt) but geographic distances are not correlated with genetic distances, i.e. these specimens show little genetic separation with respect to other representatives of their clades.

Other parallel examples are known from different African small mammals. Records of the synanthropic rodent Arvicanthis niloticus in the Sudanese Nile may be related to the expansion of early humans from central Africa northwards along the Nile Valley 177,00064,000 years ago [31]. The rodent Mus jotterandi is thought to have migrated from sub-Saharan Africa to 
Morocco during the Middle Pleistocene (0.8-0.1 Ma) [32]. Similar patterns can be invoked to explain occurrence of the C. olivieri complex in northern Africa. The Sanaga River is recognized as a barrier to dispersal for several mammal taxa [5,21]. However, animals associated with clade III are recorded from both sides of this river. This clade probably originated in dry savannah and its distribution may be linked to human movements from northern dry Cameroon to the south, even across Sanaga.

\section{Insight into the systematics of the $C$. olivieri complex}

Recent molecular data have shown paraphyly within $C$. olivieri and close phylogenetic relationships with $C$. viaria and C. fulvastra; all three taxa are also genetically close to C. goliath $[11,33]$. Our study sheds new light on the taxonomy of the complex. Based on a combination of mitochondrial and nuclear data, C. goliath from the Congo Basin appears to be monophyletic (clade V). Crocidura olivieri is polyphyletic and divided into five geographical clades showing allopatric or parapatric distributions. Molecular data from specimens collected close to the type locality of the nominate form (Sakkara, Egypt) were obtained (FMNH 68262 and 89608 from Kom Oshim and Abu Rawash, respectively) and their assignment to clade IV-B suggests that clade IV represents C. olivieri sensu stricto. Specimens of $C$. viaria and $C$. fulvastra are included in the well-supported clade III with parapatric distributions vis-à-vis other clades. Owing to the weakness of the phylogenetic signal, reciprocal monophyly of the two species could not be assessed. Dubey et al. already mentioned the paraphyly of C. olivieri with respect to C. viaria and C. fulvastra [11].

However, owing to aspects of sample size, number of base pairs employed and distribution of collection sites, Dubey et al. [11] did not recover the clades VI, VII and VIII and several nodes in their phylogeny were not wellsupported. Genetic distances between clades I to IV range from $1.34 \%$ to $2.70 \%$ based on cytb data. These values fall within the range of intraspecific variation described for the genus Crocidura (0.4-8.9\% [34]; 0-3.4\% [35]) and well below interspecific variation (14.3-20.6\% [34]; 5.5-23.5\% [35]). Based on the COI marker, genetic distances between clades I to IV range from $2.15 \%$ to $3.28 \%$. The range of intraspecific variation described for the genus Crocidura is $0-2.9 \%$ and that of interspecific variation 4.4-24.7\% [35]. Our results therefore question the taxonomic status of C. viaria and C. fulvastra. On the other hand, the clades VI, VII and VIII may represent separate species, with the level of genetic divergence comparable to C. goliath. Crocidura somalica (clade VII), described from Middle Webi Shebeli near Geledi, Ethiopia, is part of the C. olivieri complex. On the basis of morphology, animals falling within clade
VIII match the description of C. occidentalis hera Dollman, 1915 named from Shire Highlands, Malawi. This locality and localities 101 and 107 (clade VIII) are in close proximity and are isolated from adjacent landscapes by the Shire River to the west, the Zambezi River to the south and dry lowland savannah to the east. These results indicate that the C. oliveri complex is in need of a taxonomic revision, best accomplished with combined data on genetics, morphology and ecology.

\section{Conclusions}

Our study sheds new light on the evolutionary history and genetic diversity of the C. oliveri complex. Using sampling encompassing the known geographical range of the complex, a combination of mitochondrial and nuclear data and several analyses (phylogenetic inference, genetic structure analyses and divergence time estimates), we propose an evolutionary scenario for this complex. We postulate an origin in central/eastern Africa followed by a colonization and radiation in rain forests of the Congo Basin. An emigration from this biotope took place approximately $1.13 \mathrm{Ma}$. Members of the complex then colonized eastern and western Africa across a considerable range of savannah and forest habitats. Cladogenesis events and changes in habitat and ecology were probably influenced by climatic oscillations during the last 1 Myr. We tested several models providing insights into underlying mechanisms associated with the diversification of the complex and found that a variety of factors can explain their current phylogeographic structure and distribution: Pleistocene forest refuges, riverine barriers, differentiation along environmental gradients and probable human related introductions.

This study reveals the need of taxonomic revision of the $C$. olivieri complex. We confirm the validity of $\mathrm{C}$. goliath from the Congo Basin but, however, C. olivieri appears polyphyletic and divided into five geographical clades showing allopatric or parapatric distributions. We did not recover monophyly of C. viaria and C. fulvastra owing to their close genetic relationships. Values of genetic distances between clades I to IV (composed of specimens morphologically identified as C. olivieri, C. viaria and C. fulvastra) fall well below interspecific variation described among shrews, suggesting their merger into a single and widespread species. Clades VI, VII (C. somalica) and VIII may represent separate species, pending on a revision of available taxon names.

\section{Methods \\ Biological material}

For this study, we gathered 565 specimens (434 $C$. olivieri, 35 C. viaria, 13 C. fulvastra, 81 C. goliath and 
two $C$. somalica that had been identified based on morphological characters) from 128 localities on the African continent (Figure 1, Additional file 6). Our research was approved by the "Comité Cuvier d'éthique en matière d'expérimentation animale" (referral number 68.009). Animals were handled under the guidelines of the American Society of Mammalogists [36]. All samples were collected in strict compliance with local legislations, especially with the agreement of the Ministère des Eaux et Forêts in Côte d'Ivoire; the Ministère de la Recherche Scientifique et de l'Innovation in Cameroon; the Direction de la Faune et de la Chasse in Gabon; the Ministère de l'Environnement, des Eaux et Forêts et du Développement Durable in Guinea; the Wildlife Conservation Authority in Ethiopia; the Forest Service in Kenya; the Wildlife Authority in Zambia; the Institut National pour l'Environnement et la Conservation de la Nature in Burundi; the Department of Game and Wildlife Authority in Uganda; the Institut Congolais pour la Conservation de la Nature and the Centre de Recherche des Sciences Naturelles in DRC; the Wildlife Conservation Society and Development Board in Rwanda; and the Gorongosa Restoration Project in Mozambique. Specimens were not concerned by restrictions regarding the Convention on Biological Diversity and the Convention on the Trade in Endangered Species of Wild Fauna and Flora.

\section{Modern and ancient DNA extraction and amplification}

Fresh tissues were stored in 95\% ethanol. DNA was extracted from liver, kidney or intercostal tissues using the NucleoSpin96 tissue kit (Machery-Nagel). We amplified three mitochondrial markers, two being protein-coding, cytochrome oxidase I (COI, $702 \mathrm{bp}$ ) and cytochrome $b$ (cytb, $1166 \mathrm{bp}$ ), and one ribosomal, 16S (535 bp); and four nuclear markers, one exon, Breast Cancer 1 (BRCA1, 888 bp) and three introns, Signal Transducer and Activator of Transcription 5A (STAT5A, $598 \mathrm{bp}$ ), Histone Deacetylase 2 (HDAC2, 617 bp) and RIO Kinase 3 (RIOK3, 799 bp) (see Additional file 7) following the protocol in [9].

The three mitochondrial markers were chosen for their demonstrated high resolution for shrews and mammals at the specific and intraspecific levels [35,37]. The four nuclear markers had already been tested with shrews $[9,38,39]$. The use of several genetically independent loci improves the efficiency and robustness of taxa identification based on molecular data [40] and allows the detection of problems such as incomplete lineage sorting, hybridizing/introgression, retention of ancestral polymorphism, and paralogy resulting from transfer of mitochondrial DNA gene copies to the nucleus [41].

The extraction protocol we employed for ancient DNA has been extensively used for various sources of degraded DNA [42]. Herein samples consisted of dried tissue scraped from the cranium and mandible (four specimens of $C$. olivieri from Egypt collected in the 1950s close to Sakkara, the type locality) or last phalanx from one digit from mounted specimens (one C. olivieri and one C. fulvastra from Chad, three C. viaria from Senegal). We only succeeded in amplifying the two mitochondrial markers $16 \mathrm{~S}$ and COI using specific internal primers. $\mathrm{PCR}$ conditions were initial denaturation of $3 \mathrm{~min}$ at $95^{\circ} \mathrm{C}$, then 45 cycles of $95^{\circ} \mathrm{C} 10 \mathrm{~s}, 60^{\circ} \mathrm{C} 10 \mathrm{~s}$, $72^{\circ} \mathrm{C} 20 \mathrm{~s}$, and a final extension step at $72^{\circ} \mathrm{C}$ for $7 \mathrm{~min}$. To avoid contaminations with modern DNA, all these steps were performed on separate days and in an isolated room exclusively devoted to manipulations of ancient DNA.

Purification of PCR products and cycle-sequencing reactions of both DNA strands were performed at the Génoscope (Evry, France). Sequences were edited and assembled using Sequencher 4.9 (Gene Codes Corporation, Ann Arbor, MI, USA) and deposited in GenBank (see Additional file 6).

\section{Phylogenetic analyses}

To investigate the genetic diversity within the C. olivieri complex and to test for its monophyly, closely related species were included in the sampling [11] (see Additional file 6). Trees were rooted by specifying Suncus megalura and S. murinus as outgroups. For each marker, alignment was performed using ClustalW [43] (see Additional file 8). In order to assess phylogenetic relationships, among the 565 specimens, 491 were sequenced for the $16 \mathrm{~S}$ marker, 436 for cytb, 311 for COI, 92 for BRCA1, 57 for STAT5A, 45 for HDAC2 and 49 for RIOK3; the lower number of sequenced samples for certain markers was to reduce costs of laboratory work and also due to difficulties in amplifying nuclear markers, but nuclear sequences were obtained for almost all mtDNA-defined lineages. We first tested for signs of positive selection affecting the coding nuclear marker BRCA using Datamonkey server and the SLAC method [44]. We also used the GARD method [45] to detect potential signs of recombination in each nuclear alignment. Neither positive selection nor recombination was detected in our dataset (significance level of 0.01). Phylogenetic relationships were inferred for each marker separately using Bayesian Inference (MrBayes version 3.1 [46]) following procedures described by Jacquet et al. [9]. No well-supported conflict was observed between topologies, so we built a restricted data set, corresponding to the seven markers combined (5305 bp) by retaining only one specimen per locality and per clade (156 specimens, see Additional file 6). A partition for each marker was defined. We also performed analyses using mtDNA and nuclear data separately. The existence of 
potential haplotype sharing between main clades revealed by phylogenetic analyses was investigated for each marker using Arlequin 3.11 [47].

K2P [48] genetic distances on the complete cytb and COI sequences were calculated among all samples (Mega 5 [49]) to compare our values to those provided in the literature. Uncorrected p-distances were also calculated.

\section{Divergence time estimates}

A direct calibration of a molecular clock within the $C$. olivieri complex was not possible, because of the lack of a fossil record of this group in Africa [50]. Therefore, we used five external calibration points treated as minimum age constraints: split between Soricinae and CrocidurinaeMyosoricinae $20 \mathrm{Ma}$ [51], oldest recorded MyosoricinaeCrocidurinae representative $12 \mathrm{Ma}$ [52], oldest record of Crocidura (C. kapsominensis) $6 \mathrm{Ma}$ [53], oldest Otisorex $3.5 \mathrm{Ma}$ [54] and oldest Cryptotis $9 \mathrm{Ma}$ [55]. We used sequences of the three mitochondrial markers and no nuclear marker because of the deep coalescence of the latter. Two specimens of the C. olivieri complex were selected within each clade I to VIII revealed by phylogenetic analyses. Each of these two specimens belonged to divergent subclades. Several specimens belonging to Soricidae species were also included to use calibration points described above. Trees were rooted by specimens of Talpa europaea and Uropsilus soricipes.

Times of divergence and credibility intervals were inferred using a Bayesian analysis implemented with BEAST 1.6.2 [56] under a Yule model. We used a lognormal relaxed molecular clock model [57], because phylogenetic rates obtained from the external ancient calibrations could be inapplicable for dating recent events ( $<1-2$ Mya) due to rate decay [58]. All fossil calibration ages were treated as lognormal distributions [57], except the divergence between Soricinae and Crocidurinae-Myosoricinae that was used as a constraint [59] and thus treated as normal distribution. Posterior distributions of parameters were approximated using two independent MCMC analyses of 100,000,000 generations each. The first $10 \%$ of trees were discarded, and a $50 \%$ consensus tree was constructed from the remaining trees. We checked similarity of results from the two runs, and samples were then combined. Convergence of the chains was checked using the program TRACER 1.3 [60]. To check compatibility of calibration points, a cross-validation was used by repeating the analysis several times, leaving out in turn one of the calibrations and comparing node ages estimations. The maximum divergence in these estimations was observed between the topologies obtaining after leaving out the Cryptotis $(9 \mathrm{Ma})$ and Otisorex (3.5 Ma) calibration points, respectively. Values of divergence for nodes within the $C$. olivieri complex were comprised between 6.6 and 9.5\%. The analysis was also performed using a standard mammalian mutation rate (2.2\% per Myr [18]).

\section{Estimates of genetic diversity, genetic structure and historical demography}

Genetic diversity, genetic structure and historical demography were estimated for the major clades revealed by our phylogenetic analyses using combined data from the three mitochondrial markers (267 specimens for which all three markers $16 \mathrm{~S}$, cytb and COI were available). $\mathrm{Nu}$ clear markers were not employed because of their much lower variability. Number of sequences, polymorphic sites, haplotypes and nucleotide differences, and the haplotype and nucleotide diversities were estimated using Arlequin 3.11.

Several procedures were undertaken to test the hypothesis of recent population growth. Mismatch distributions [61], Tajima's $D$ [62], Fu and Li's $F^{*}$ and $D^{*}$ [63] and Fu's Fs tests [64] were calculated using Arlequin 3.11 and DnaSP 4.50.2 [65], and following the procedure described by Nicolas et al. [15]. An extended skyline plot analysis using BEAST 1.6.2 was generated to estimate an expansion based on multiple loci.

\section{Availability of supporting data}

The sequence data supporting the results of this article are available in the GenBank repository [http:// www.ncbi.nlm.nih.gov/genbank]. Accession numbers are provided in Additional file 6.

\section{Additional files}

Additional file 1: Concatenated tree file. File containing the topology of the tree built using Bayesian Inference and data from seven markers (165, cytb, COI, BRCA1, STAT5A, HDAC2 and RIOK3) in .tre format.

Additional file 2: Mitochondrial topology. Phylogenetic tree built using Bayesian Inference and data from three mitochondrial markers (16S, cytb and COI) for 156 specimens of the C. olivieri complex. Values above branches are Bayesian posterior probabilities. The branchlets are identified by specimen numbers defined in Additional file 6

Additional file 3: Mitochondrial tree file. File containing the topology of the tree built using Bayesian Inference and data from three mitochondrial markers (16S, cytb and COI) in .tre format.

Additional file 4: Nuclear topology. Phylogenetic tree built using Bayesian Inference and data from four nuclear markers (BRCA1, STAT5A, HDAC2 and RIOK3) for 37 specimens of the C. olivieri complex. Values above branches are Bayesian posterior probabilities. The branchlets are identified by specimen numbers defined in Additional file 6 .

Additional file 5: Nuclear tree file. File containing the topology of the tree built using Bayesian Inference and data from four nuclear markers (BRCA1, STAT5A, HDAC2 and RIOK3) in .tre format.

Additional file 6: Information on specimens used in this study. Specimens used for molecular analyses with details of localities (locality number based on Figure 1 and coordinates in decimal degrees), information on mitochondrial clade, number of sequenced individuals for the locality and GenBank accession numbers. Owing to difficulties in 
amplifying the whole cytb marker, internal primers were designed, leading sometimes to the submission of several sequence portions.

Additional file 7: Markers used in this study. Markers used in this study with specific primers designed to amplify cytb and COI markers.

Additional file 8: Sequence alignments. Sequence alignment in fasta format for each marker (16S, cytb, COI, BRCA1, STAT5A, HDAC2 and RIOK3) used in this study.

\section{Competing interests}

The authors declare that they have no competing interests.

\section{Authors' contributions}

FJ, CD, MC and VN conceived the idea. CD, JB, RH, JCK, WTS, SMG, MC and VN collected the samples. FJ, EV, JB, MC and VN performed the genotyping. FJ analysed genetic data and was the primary author of the manuscript. VN, $S M G, J B, R H$ and JCK actively participated in the writing of the paper. All authors read, corrected and approved the final manuscript.

\section{Acknowledgements}

Field campaigns were funded by EU-DGVIII BIOFAC and ECOFAC programs, WHO-Ebola Research Project in Côte d'Ivoire, WWF Gabon, PGRR-GFA Terra Systems Project in Guinea, PAMF Bénin, INCO-DEV Treat Control in Guinea and Côte d'Ivoire, ANR Biodiversité IFORA Cameroon, Czech Science Foundation project n P506-10-0983, Barbara Brown Fund, Ellen Thorne Smith Fund, Marshall Field III Fund, John D. and Catherine T. MacArthur Foundation and World Wide Fund for Nature and Wildlife Conservation Society. We thank the Ministère des Eaux et Forêts in Côte d'Ivoire; the Ministère de la Recherche Scientifique et de I'Innovation in Cameroon; the Direction de la Faune et de la Chasse in Gabon; the Ministère de l'Environnement, des Eaux et Forêts et du Développement Durable in Guinea, the Wildlife Conservation Authority in Ethiopia, the Forest Service and the Kenyan Wildlife Service in Kenya, the Wildlife Authority in Zambia, the Institut National pour l'Environnement et la Conservation de la Nature in Burundi, the Department of Game and Wildlife Authority in Uganda, the Institut Congolais pour la Conservation de la Nature and the Centre de Recherche des Sciences Naturelles in DRC, the Wildlife Conservation Society and Development Board in Rwanda, and the Gorongosa Restoration Project and the Museu de História Natural in Mozambique for permission to work in the respective countries. We thank the Service de Systématique Moléculaire (UMS2700) of the MNHN where most laboratory work was performed. This work is part of the project @ SPEED-ID, the French Barcode of Life Initiative and the Belgian Science Policy (BELSPO) project 31.64. We are grateful to curators for making museum specimens available: FMNH, Chicago; PFIAO, Cape Town; MCZ, Cambridge; IVB ASCR, Brno; University of South Bohemia, České Budějovice; CBGP, Montferrier-sur-Lez; Université de Cocody-Abidjan, Abidjan; ZFMK, Bonn; University of Vermont, Burlington; Guelph University, Guelph; ITM and University of Antwerp, Antwerp; Kogi State University, Anyigba; SMNS, Stuttgart; and IZEA, Lausanne. We gratefully acknowledge F. Catzeflis and collaborators, H. Leirs, W. Verheyen, B Kadjo, J. Decher, L. Durnez, G. Dobigny, C. Tatard, L. Granjon and A. Olayemi who kindly provided tissue samples; A. Konečný, R. Šumbera, V. Mazoch, J. Mbau and Y. Meheretu for help in the collection of specimens; and S. Quérouil, P. Barrière and T. Dillen for participation in sequencing work. We are grateful to R. Debruyne who helped to obtain ancient DNA sequences. We are also grateful to the two anonymous reviewers for constructive feedback and insightful suggestions, which greatly improved this article.

\section{Author details}

${ }^{1}$ Institut de Systématique, Évolution, Biodiversité, ISYEB UMR 7205 - CNRS, MNHN, UPMC, EPHE, Muséum National d'Histoire Naturelle, Sorbonne Universités, 57 rue Cuvier, CP 51, 75005 Paris, France. ${ }^{2}$ Royal Belgian Institute of Natural Sciences, Operational Direction Taxonomy and Phylogeny, Molecular Laboratory, Vautierstraat 29, 1000 Brussels, Belgium. ${ }^{3}$ Biology Department, University of Antwerpen, Evolutionary Ecology Group, Groenenborgerlaan 171, 2020 Antwerpen, Belgium. ${ }^{4}$ Institute of Vertebrate Biology ASCR, Academy of Sciences of the Czech Republic, Květná 8, 60365 Brno, Czech Republic. ${ }^{5}$ Department of Botany and Zoology, Faculty of Science, Masaryk University, Kotlářská 2, 61137 Brno, Czech Republic. ${ }^{6}$ Zoologisches Forschungmuseum Alexander Koenig, Adenauerallee 160, D-53113 Bonn, Germany. ${ }^{7}$ College of Professional Studies, Roosevelt University, 430 S Michigan Avenue, Chicago, IL 60605, USA. ${ }^{8}$ Field Museum of
Natural History, 1400 South Lake Shore Drive, Chicago, IL 60605, USA. ${ }^{9}$ Association Vahatra, BP 3972, Antananarivo 101, Madagascar. ${ }^{10}$ Génoscope, Centre National de Séquençage, 2 rue Gaston Crémieux, CP5706, 91057 Evry Cedex, France. ${ }^{11}$ Université de Rennes 1, CNRS, UMR 6553 Ecobio, Station Biologique, 35380 Paimpont, France.

Received: 11 November 2014 Accepted: 30 March 2015 Published online: 23 April 2015

\section{References}

1. Maley J. African rain forest ecology and conservation. An interdisciplinary perspective. In: Weber W, White L, Vedder A, Naughton-Treves L, editors. The impact of arid phases on the African rain forest through geological history. New Haven: Yale University Press; 2001. p. 68-87.

2. deMenocal PB. African climate change and faunal evolution during the Pliocene-Pleistocene. Earth Planet Sci Lett. 2004;220:3-24.

3. Arctander P, Johansen C, Coutellec-Vreto MA. Phylogeography of three closely related African bovids (tribe Alcelaphini). Mol Biol Evol. 1999;16:1724-39.

4. Dubach JM, Patterson BD, Briggs MB, Venzke K, Flammand J, Stander P, et al. Molecular genetic variation across the southern and eastern geographic ranges of the African lion, Panthera leo. Conserv Genet. 2005; :15-24.

5. Anthony NM, Johnson-Bawe M, Jeffery K, Clifford SL, Abernethy KA, Tutin $C E$, et al. The role of Pleistocene refugia and rivers in shaping gorilla genetic diversity in Central Africa. Proc Natl Acad Sci U S A. 2007;104:20432-6.

6. Nicolas V, Mboumba JF, Verheyen E, Denys C, Lecompte E, Olayemi A, et al. Phylogeographical structure and regional history of Lemniscomys striatus (Rodentia: Muridae) in tropical Africa. J Biogeogr. 2008;35:2072-89.

7. Olayemi A, Nicolas V, Hulselmans J, Missoup AD, Fichet-Calvet E, Amundala D, et al. Taxonomy of the African giant pouched rats (Nesomyidae: Cricetomys): molecular and craniometric evidence support an unexpected high species diversity. Zool J Linn Soc. 2012;165:700-19.

8. Colangelo P, Verheyen E, Leirs H, Tatard C, Denys C, Dobigny G, et al. A mitochondrial phylogeographic scenario for the most widespread African rodent, Mastomys natalensis. Biol J Linn Soc. 2013;108:901-16.

9. Jacquet F, Nicolas V, Colyn M, Kadjo B, Hutterer R, Akpatou B, et al. Forest refugia and riverine barriers promote diversification in the West African pygmy shrew (Crocidura obscurior complex, Soricomorpha). Zool Scr. 2013;43:131-48.

10. Wójcik JM, Wolsan M. Evolution of shrews. Bialowieza: Mammal Research Institute, Polish Academiy of Sciences; 1998.

11. Dubey S, Antonin M, Denys C, Vogel P. Use of phylogeny to resolve the taxonomy of the widespread and highly polymorphic African giant shrews (Crocidura olivieri group, Crocidurinae, Mammalia). Zool. 2007;110:48-57.

12. Churchfield S, Hutterer R. Crocidura olivieri, African Giant Shrew. In: Happold M, Happold DCD, editors. Mammals of Africa, vol. Volume IV. London: Bloomsbury Publishing; 2013. p. 118-9.

13. Gascon C, Malcolm JR, Patton JL, da Silva MNF, Bogart JP, Lougheed SC, et al. Riverine barriers and the geographic distribution of Amazonian species. Proc Natl Acad Sci U S A. 2000;97:13672-7.

14. Katuala PGB, Kennis J, Nicolas V, Wendelen W, Huselmans J, Verheyen E, et al. The presence of Praomys, Lophuromys, and Deomys species (Muridae, Mammalia) in the forest blocks separated by the Congo River and its tributaries (Kisangani region, Democratic Republic of Congo). Mammalia. 2008;72:223-8.

15. Nicolas V, Bryja J, Akpatou B, Konečný A, Lecompte E, Colyn M, et al. Comparative phylogeography of two sibling species of forest-dwelling rodent (Praomys rostratus and P. tullbergi) in West Africa: different reactions to past forest fragmentation. Mol Ecol. 2008;17:5118-34.

16. Nicolas V, Akpatou B, Wendelen W, Kerbis Peterhans J, Olayemi A, Decher J, et al. Molecular and morphometric variation in two sibling species of the genus Praomys (Rodentia: Muridae): implications for biogeography. Zool J Linn Soc. 2010;160:397-419.

17. Smith $T B$, Schneider $C J$, Holder K. Refugial isolation versus ecological gradients. Genetica. 2001;112:383-98.

18. Kumar S, Subramanian S. Mutation rates in mammalian genomes. Proc Natl Acad Sci U S A. 2002;99:803-8.

19. Heled J, Drummond AJ. Bayesian inference of population size history from multiple loci. BMC Evol Biol. 2008;8:289. 
20. Maley J. The African rain forest - main characteristics of changes in vegetation and climate from the Upper Cretaceous to the Quaternary. P Roy Soc Edinb A. 1996;104B:31-73.

21. Telfer PT, Souquiere S, Clifford SL, Abernethy KA, Bruford MW, Disotell TR, et al. Molecular evidence for deep phylogenetic divergence in Mandrillus sphinx. Mol Ecol. 2003;12:2019-24.

22. Anhuf D, Ledru MP, Behling H, Da Cruz FW, Cordeiro RC, Van der Hammen $T$, et al. Paleo-environmental change in Amazonian and African rainforest during the LGM. Palaeogeogr Palaeocl. 2006;239:510-27.

23. White F. Vegetation Map of Africa. Oxford: Oxford University Press; 1981.

24. Dobigny G, Aniskin V, Granjon L, Cornette R, Volobouev V. Very recent radiation in West African Taterillus: the concerted role of chromosome and climatic changes. Heredity. 2005;95:358-68.

25. Flugel T, Eckardt FD, Cotterill FPD. The present day drainage patterns of the Congo river system and their Neogene evolution. In: de Wit MJ, Guillocheau F, de Wit MCJ, editors. Geology and Resource Potential of the Congo Basin. Berlin: Springer; 2015. p. 315-37.

26. Gambalemoke M, Mukinzi I, Amundala D, Katuala G, Kennis J, Dudu A, et al. Shrew trap efficiency: experience from primary forest, secondary fallow land and old palm plantation in the Congo River Basin, Democratic Republic of Congo. Mammalia. 2008;72:203-12.

27. Nicolas V, Barrière $P$, Tapiero A, Colyn M. Shrew species diversity and abundance in Ziama Biosphere Reserve (Guinea): comparison between primary forest, degraded forest and restoration plots. Biodiversity Conserv. 2009:18:2043-61.

28. Thorpe RS, McGregor DP, Cumming AM, Jordan WC. DNA evolution and colonization sequence of island lizards in relation to geological history: mitochondrial, RFLP, cytochrome B, cytochrome oxidase, 12S RNA sequence, and nuclear RAPD analysis. Evolution. 1994;48:230-40.

29. Heim de Balsac H. Les Soricidae dans le milieu désertique saharien. Bonn Zool Beitr. 1968;19:181-8.

30. Hutterer R, Happold DCD. The shrews of Nigeria. Bonn Zool Monogr. 1983;18:1-79.

31. Abdel Rahman Ahmed EH, Ducroz JF, Mitchell A, Lamb J, Contrafatto G Denys $C$, et al. Phylogeny and historical demography of economically important rodents of the genus Arvicanthis (Mammalia: Muridae) from the Nile Valley: of mice and men. Biol J Linn Soc. 2008;93:641-55.

32. Stoetzel E, Denys C, Michaux J, Reynaud S. Mus in Morocco: a Quaternary sequence of intraspecific evolution. Biol J Linn Soc. 2013;109:599-621.

33. Jacquet F, Hutterer R, Nicolas V, Decher J, Colyn M, Couloux A, et al. New status for two African giant forest shrews, Crocidura goliath goliath and $C$. goliath nimbasilvanus (Mammalia: Soricomorpha), based on molecular and geometic morphometric analyses. Afr Zool. 2013;48:13-29.

34. Vogel P, Cosson JF, Lopez Jurado LF. Taxonomic status and origin of the shrews (Soricidae) from the Canary Islands inferred from a mitochondrial comparison with the European Crocidura species. Mol Phylogenet Evol. 2003;27:271-82

35. Jacquet F, Nicolas V, Bonillo C, Cruaud C, Denys C. Barcoding, molecular taxonomy and exploration of the diversity of shrews (Soricomorpha: Soricidae) on Mount Nimba (Guinea). Zool J Linn Soc. 2012;166:672-87.

36. Sikes RS, Gannon WL, Animal Care Committee of the American Society of Mammalogists. Guidelines of the American Society of Mammalogists for the use of wild mammals in research. J Mammal. 2011:92:235-53.

37. Pfunder M, Holzgang O, Frey JE. Development of microarray-based diagnostics of voles and shrews for use in biodiversity monitoring studies, and evaluation of mitochondrial cytochrome oxidase I vs. cytochrome $b$ as genetic markers. Mol Ecol. 2004;5:1277-86

38. Dubey S, Salamin N, Ruedi M, Barrière P, Colyn M, Vogel P. Biogeographic origin and radiation of the Old World crocidurine shrews (Mammalia: Soricidae) inferred from mitochondrial and nuclear genes. Mol Phylogenet Evol. 2008;48:953-63.

39. Willows-Munro S, Matthee CA. The evolution of the southern African members of the shrew genus Myosorex: understanding the origin and diversification of a morphologically cryptic group. Mol Phylogenet Evol. 2009;51:394-8.

40. Austerlitz F, David O, Schaeffer B, Bleakley K, Olteanu M, Leblois R, et al. DNA barcode analysis: a comparison of phylogenetic and statistical classification methods. BMC Bioinform. 2009;10:S10.

41. Hurst GDD, Jiggins FM. Problems with mitochondrial DNA as a marker in population, phylogeographic and phylogenetic studies: the effects of inherited symbionts. P Roy Soc Lond B Bio. 2005;272:1525-34
42. Debruyne R, Schwarz C, Poinar H. Comment on "Whole-genome shotgun sequencing of mitochondria from ancient hair shafts. Science. 2008;322:857.

43. Thompson JD, Higgins DG, Gibson TJ. Clustal W: improving the sensitivity of progressive multiple sequence alignment through sequence weighting, position-specific gap penalties and weight matrix choice. Nucleic Acids Res. 1994;22:4673-80.

44. Kosakovsky Pond SL, Frost SDW. Datamonkey: rapid detection of selective pressure on individual sites of codon alignments. Bioinformatics. 2005;21:2531-3

45. Kosakovsky Pond SL, Posada D, Gravenor MB, Woelk CH, Frost SDW. Automated phylogenetic detection of recombination using a genetic algorithm. Mol Biol Evol. 2006;23:1891-901.

46. Huelsenbeck JP, Ronquist F, Nielsen R, Bollback JP. Bayesian inference of phylogeny and its impact on evolutionary biology. Science. 2001;294:2310-4

47. Excoffier L, Laval G, Schneider S. Arlequin version 3.0: an integrated software package for population genetics data analysis. Evol Bioinform Online. 2005;1:47-50.

48. Kimura M. A simple method for estimating evolutionary rate of base substitutions through comparative studies of nucleotide sequences. J Mol Evol. 1980;16:111-20

49. Tamura K, Peterson D, Peterson N, Stecher G, Nei M, Kumar S. MEGA5: Molecular Evolutionary Genetics Analysis using Maximum Likelihood, Evolutionary Distance, and Maximum Parsimony Methods. Mol Biol Evol. 2011;28:2731-9.

50. Butler PM. Neogene Insectivora. In: Werdelin L, Sanders WJ, editors. Cenozoic mammals of Africa. Berkeley: University of California Press; 2010. p. 573-80.

51. Reumer JWF. Speciation and evolution in the Soricidae (Mammalia: Insectivora) in relation with the paleoclimate. Rev Suisse Zool. 1989:96:81-90.

52. Robinson P, Black CC. Vertebrate faunas from the Neogene of Tunisia. Ann Geol Surv Egypt. 1974:4:319-32.

53. Mein P, Pickford M. Late Miocene micromammals from the Lukeino Formation (6.1 to 5.8 Ma), Kenya. Bull Mens Soc Linn Lyon. 2006:75:183-223.

54. Maldonado JE, Vila C, Wayne RK. Tripartite genetic subdivisions in the ornate shrew (Sorex ornatus). Mol Ecol. 2001;10:127-47.

55. Harris AH. Fossil history of shrews in North America. In: Wojcik JM, Wolsan M, editors. Evolution of Shrews. Bialowieza: Mammal Research Institute, Polish Academy of Science; 1998. p. 121-32.

56. Drummond AJ, Rambaut A. BEAST: Bayesian evolutionary analysis by sampling trees. BMC Evol Biol. 2007;7:214

57. Drummond AJ, Ho SYW, Phillips MJ, Rambaut A. Relaxed phylogenetics and dating with confidence. PLoS Biol. 2006;4:699-710.

58. Ho SYW, Shapiro B, Phillips M, Cooper A, Drummond AJ. Evidence for time dependency of molecular rate estimates. Syst Biol. 2007;56:515-22.

59. Fumagalli L, Taberlet P, Stewart DT, Gielli L, Hausser J, Vogel P. Molecular phylogeny and Evolution of Sorex shrews (Soricidae: Insectivora) inferred from mitochondrial DNA sequence data. Mol Phylogenet Evol. 1999:11:222-35.

60. Rambaut A, Drummond AJ. Tracer v1.4. Available via http:// beast.bio.ed.ac.uk/Tracer. 2007.

61. Rogers AR, Harpending H. Population growth makes waves in the distribution of pairwise genetic differences. Mol Biol Evol. 1992;9:552-69.

62. Tajima $F$. The effect of change in population size on DNA polymorphism Genetics. 1989;123:597-601.

63. Fu YX, Li WH. Statistical tests of neutrality of mutations. Genetics. 1993;133:693-709.

64. Fu YX. Statistical tests of neutrality of mutations against population growth, hitchhiking and background selection. Genetics. 1997;147:915-25.

65. Rozas J, Sanchez-De I, Barrio JC, Messeguer X, Rozas R. DnaSP, DNA polymorphism analyses by the coalescent and other methods. Bioinformatics. 2003;19:2496-7. 